\title{
Design of oscillation wireless charging system based on time-base circuit
}

\author{
Bo Zhang ${ }^{1}$, Zhong rui Wang ${ }^{1}$ \\ ${ }^{I}$ Department of Telecommunication and Information Engineering, Xi'An University of Science and Technology, Xi'An, 710054, CHINA \\ "Corresponding Author: e-mail: 2360424683@qq.com, Tel +86-029-85583114, Fax.+86-029-85583114
}

\begin{abstract}
With the application of a large number of portable low-voltage electronic products, the charging safety of the equipment needs to be solved because of the complex underground environment and high temperature and humidity. An oscillatory wireless charging platform based on 555 time base circuit is developed in this paper. The transmitter circuit is mainly composed of PWM waveform generator and MOS switch circuit. The frequency adjustable output range can reach $500 \mathrm{kHz}$, and no program control unit is required. The receiver circuit can output $5 \mathrm{~V}$ DC power stably and simply. The whole charging platform has few components at both ends of the receiver, which can ensure low failure rate and easy miniaturization. All the components are universal components with low cost. The tested transmission distance can work stably within $20 \mathrm{CM}$, and the stable output of about 3 watts can be obtained. The system can be installed in any position in the mine, and the battery is not removed when charging, which greatly enhances the security of the charging process and is of great practical value.
\end{abstract}

Keywords: NE555, Waveform generating Circuit, Resonance Circuit, receiving Coil

DOI: http://dx.doi.org/10.4314/ijest.v10i2.3

\section{Introduction}

The underground space is small and the ambient temperature and humidity are high. Usually, small-scale low-voltage power equipments are charged on the wells. In order to ensure battery life, it is sometimes necessary to carry spare batteries or smallsized charging equipment. With the application of a large number of intelligent products down hole, the equipment's cruising ability and weight have become the main contradiction, and down hole also needs an efficient charging method to solve the problem of electronic equipment life. Down hole use of transformers, adapters and other DC wired charging equipment charging, has a certain potential safety hazards, the design of circuit protection, as well as the design of the charging management unit have high requirements, will lead to high costs and inconvenience.

At present, the wireless charging technology and equipment in the wells have been widely used, not only can quickly charge small smart electronic devices, but also can be used to charge large electric devices such as electric vehicles, but the use of electromagnetic induction technology, the technology transmission distance is very short, generally Within 100mm, it is necessary to accurately position the transmitting coil and receiving coil to improve the coupling performance, to obtain higher energy transmission efficiency, and not to charge multiple devices at the same time. Although the effect of non-contact charging is achieved, the actual use and Compared with wired charging methods, there is no obvious advantage (Maochun et al., 2009). In this paper, a waveform generator circuit based on time-base circuit is developed as a transmitter, transceiver coil and energy receiver. The design of the transceiver coil can be freely moved, and the designed circuit is relatively simple and easy to implement. This design can be applied to some places where the distance transmission is not demanding. Through testing, the transmission efficiency is as high as $30 \%$ within a certain distance test range, which has a very good practical value. 


\section{Transmitter oscillation circuit design}

The circuit design in this paper is based on the theory of resonant coupled radio energy transmission technology. If the resonant frequency of the energy transmitting device and the receiving device are the same, and the exciting transmitter generates an alternating magnetic field at this specific resonant frequency, the transmitting device is in this alternating magnetic field. First, self-resonance is generated and an alternating magnetic field of the same frequency is generated. When the receiving device is close to the transmitting device, self-resonance is also generated. The receiving device continuously collects energy and transmits it to the load, thus achieving wireless transmission of energy, and its transmission principle. As shown in Figure 1 (Ming, 2012).

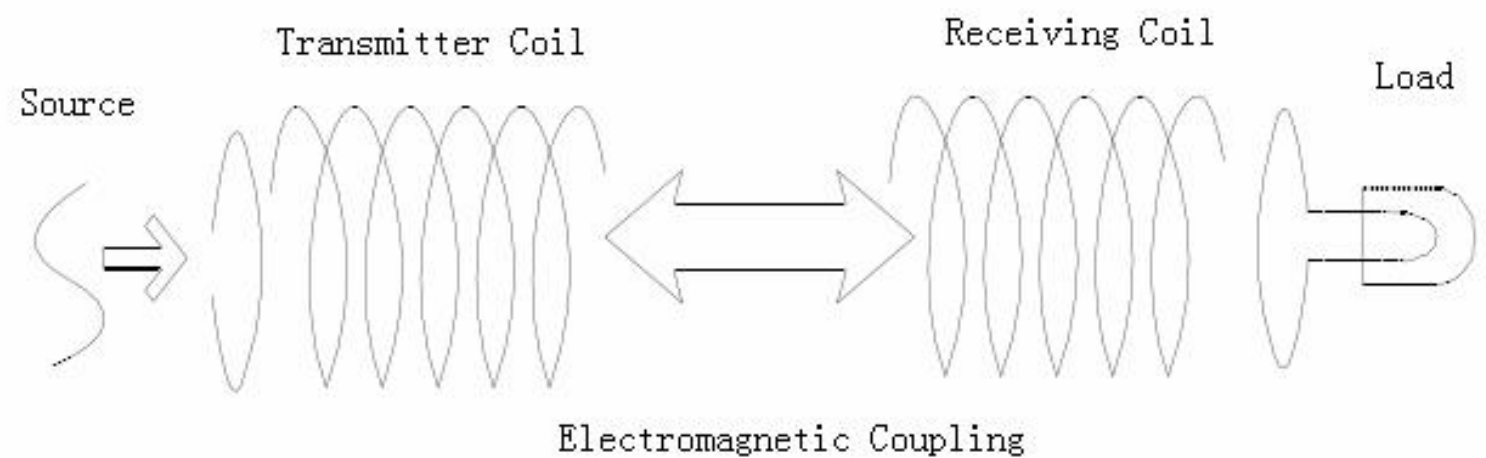

Figure 1. Schematic diagram of electromagnetic resonance coupled radio energy transmission (Ming, 2012)

The transmitter uses the NE555 time base circuit to generate the PWM signal, and the 555 time base circuit generates the PWM signal, which can generate waveforms from 1 to $500 \mathrm{KHz}$. Frequency adjustment is simple and the circuit is simple. Its principle is to add diodes and potentiometers on the basis of NE555. The schematic diagram is shown in Figure 2. In this way, an adjustable wideband modulator can be produced. In this method, NE555 is cheap, simple in design and stable. Reliable, frequency adjustment without program control (Hui et al., 2011; Kun et al., 2013).

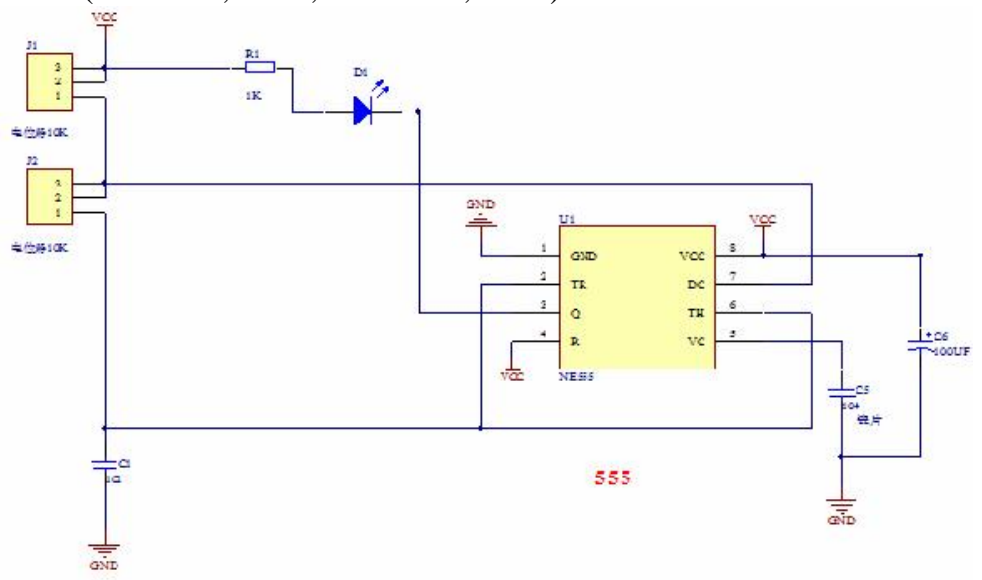

Figure 2. NE555 waveform generation circuit

This article uses a parallel resonant circuit, it is also composed of capacitors, resistors and inductors in parallel, we know that the series impedance, the AC impedance is 0 , but in the parallel impedance, the circuit resonance, its impedance is greatest, when the parallel resonance, Its path voltage and current are in the same phase, and the resonant frequency calculation formula:

$f=\frac{1}{2 \pi \sqrt{L C}}$

By calculation $f=85 \mathrm{KHz}$, where the coil inductance $L=15 \mathrm{uh}$, parallel capacitance of $0.2 \mathrm{uf}$, due to certain errors in the calculated value and the actual value, the nominal value of the capacitor and the actual value is also different, after testing at $85 \mathrm{KHz}$ frequency can produce resonance. This article uses MOS tube driver, using IRF540 constitute the drive circuit, IRF540 switch tube opening time of $4 \mathrm{~ns}$, closing time of $3 \mathrm{~ns}$, in theory, switching frequency can reach tens of $\mathrm{M}$, and low power consumption through the current fully meet the requirements, the specific design shown in Figure 1

A conventional way to plan a manuscript is to construct an outline. An outline has two interacting purposes. One is to shape the technical information in logical order and other is to help in organizing and thinking about paper. It should be flexible. The main 
text should be divided into several sections and subsection. There should be continuity in the presentation. The style of sections and subsection are generally given in the guidelines of the journal. If nothing is available, it is preferable to see the previous issue of the journal concerned. The complex mathematical derivation should be placed in the appendix of the paper, which is placed at end of the paper.

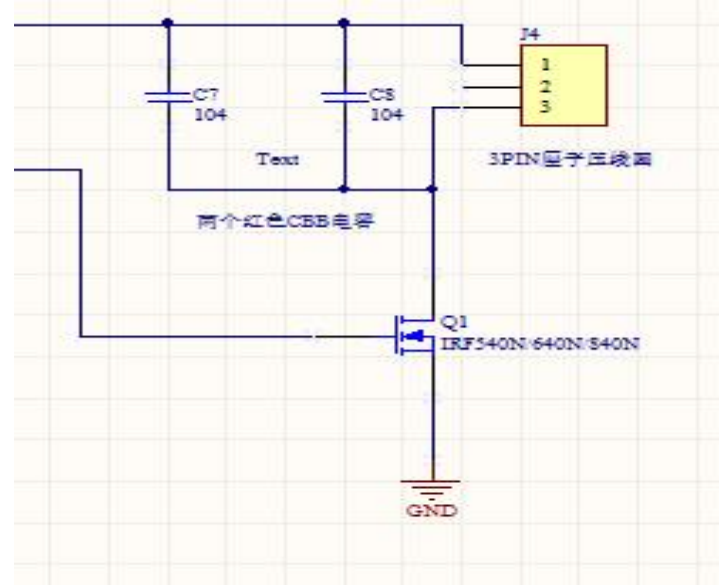

Figure 3. Design of Parallel Resonant Circuit Drive Circuit

The receiving end adopts half-bridge rectification. It is mainly to seal the two diodes of the bridge rectification together. Using two diodes, the center tap of the transformer coil is used to form a symmetry loop, and then the filter and the voltage stabilization circuit can be connected to obtain the stability of $5 \mathrm{~V}$. Output, charging small electronic devices, it is characterized by a simple structure, low cost, as shown in Figure 4.

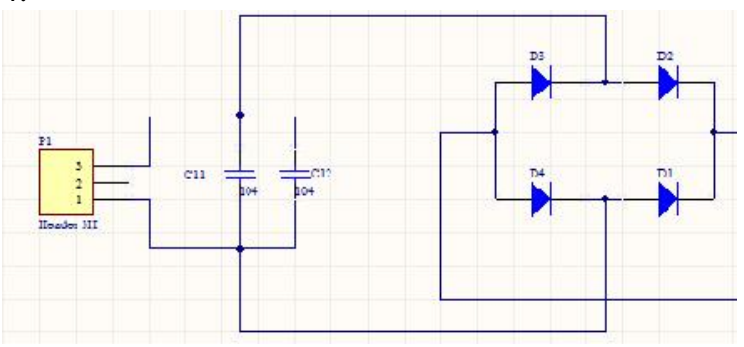

Figure 4. Receiver schematic

\section{Fabrication of transmit and receive coils}

This article adopts the enameled wire winding method to make the required transmitting and receiving coils. This method can determine the number of turns and the size of the radius of the winding according to the needs of theoretical calculations. Moreover, this kind of copper wire is convenient to purchase, and it is also convenient for recycling without use. The waste of resources.

For different coils of different structures and shapes, the calculation formula of the inductance is different. In this paper, the formula for calculating the coil inductance is:

$$
L=N^{2} r \mu_{0} \ln \left(\frac{8 r}{a}\right)-1.75
$$

In the formula, there are $\mathrm{N}-$ coil round number; $\mu_{0}-$ vacuum permeability; $\mu_{0}=4 \times 10^{-7} \mathrm{H} / \mathrm{m} ; \mathrm{r}-$ coil radius $(\mathrm{m})$; a - wire radius (m)

In this design process, an enameled wire with a diameter of $1.2 \mathrm{~mm}$ was used to make the coil. According to the previously calculated inductance value, the coil inductance needs to be around $15 u \mathrm{H}$. Finally through experiments, with the help of an electrical parameter tester, continuous testing, successfully winding the coil shown in Figure 5. 


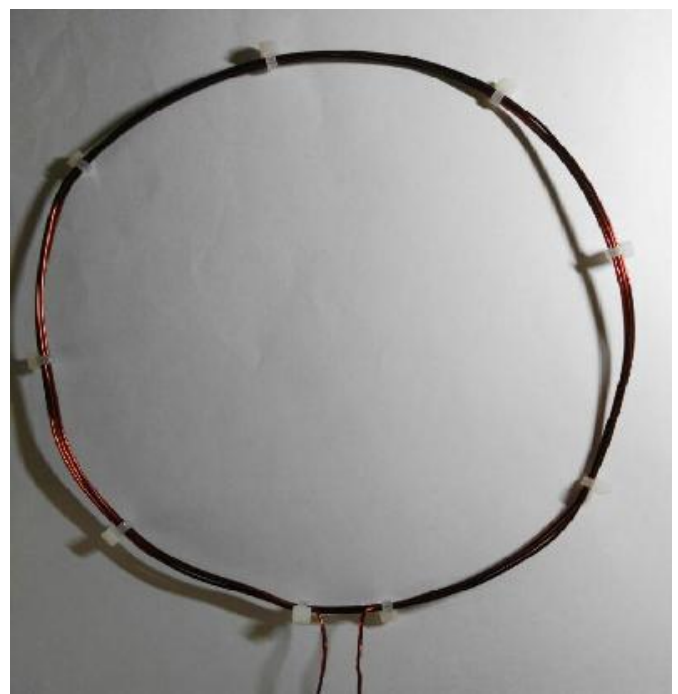

Figure 5. Coil real picture

The circular structure increases the area-to-volume ratio of the product. Therefore, the core and the coil are the best processing methods in terms of heat dissipation. The required inductance value is very small. When the coil diameter is $15 \mathrm{~cm}$, the magnet wire is by winding 4 turnings, the theoretically calculated inductance value can be obtained.

\section{Results}

When the transmitter coil is placed parallel to the receiver coil, two $1 \mathrm{~W}$ series LED lamps can be lit within $15 \mathrm{~cm}$. At the same time when the transmitter coil and the receiver coil are placed at $90^{\circ}$, the bulb can also be lit, as shown in Figure 6 .

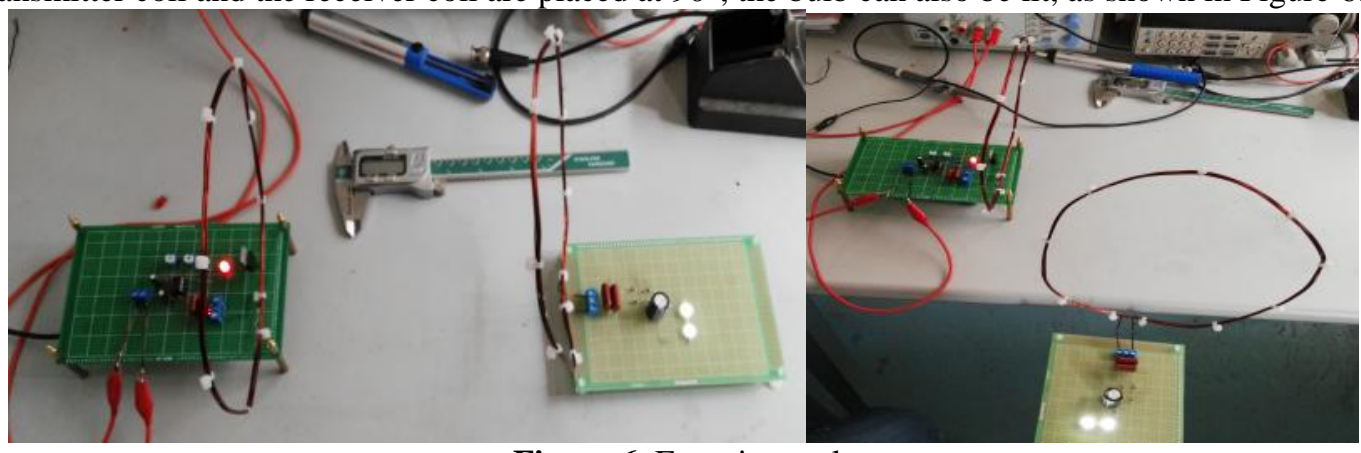

Figure 6. Experimental setup

Under the premise of inputting $15 \mathrm{~V}, 0.8 \mathrm{~A}$, the receiving end of the system uses two LEDs with a rated power of $1 \mathrm{~W}$ as the load, and sets the NE555 output oscillation signal at $200 \mathrm{KHz}$, and the coil resonant frequency is about $83 \mathrm{KHz}$. Definition of input and output power: The input power of a power supply is the product of the voltage and current at the input of the power supply. The output power of a power supply refers to the product of the voltage and current at both ends of the output of the power supply after the output of the power supply is connected to the load.

When the distance between the transmitting coil and the receiving coil changes, the strength of the magnetic field also changes, so the output voltage will change. That is, when the distance between the transmitting coil and the receiving coil increases, the magnetic field weakens and the output voltage decreases. The distance is gradually reduced, and the measured voltage, current, and power levels are shown in Table 1 below.

Table 1 Test Results

\begin{tabular}{|c|c|c|c|}
\hline Coil distanc $(\mathrm{cm})$ & The output voltage $(V)$ & Output current $(\mathrm{mA})$ & Output Power $(W)$ \\
\hline 3 & 13.2 & 150 & 1.98 \\
\hline 5 & 13.0 & 150 & 1.95 \\
\hline 7 & 12.7 & 148 & 1.89 \\
\hline 9 & 12.2 & 145 & 1.77 \\
\hline 11 & 11.2 & 141 & 1.60 \\
\hline
\end{tabular}


Table 1 (cont'd) Test Results

\begin{tabular}{|c|c|c|c|}
\hline Coil distanc $(\mathrm{cm})$ & The output voltage $(V)$ & Output current $(\mathrm{mA})$ & Output Power $(W)$ \\
\hline 13 & 10.8 & 138 & 1.50 \\
\hline 15 & 10.2 & 134 & 1.37 \\
\hline 17 & 9.3 & 129 & 1.20 \\
\hline 19 & 8.5 & 121 & 1.03 \\
\hline 21 & 7.8 & 119 & 0.93 \\
\hline 23 & 6.5 & 108 & 0.71 \\
\hline
\end{tabular}

From the above table, it can be analyzed that as the distance between the transmitting coil and the receiving coil increases, the voltage, current, and power of the output end show a trend of attenuation. This is due to the continuous weakening of the electromagnetic wave energy generated at the transmitter as the distance increases. The experimental device designed this time is in the range of $0-15 \mathrm{~cm}$ and the power is greater than $1.4 \mathrm{~W}$, which can achieve better energy transmission.

\section{Conclusion}

The circuit of this design is simple, and the circuit size can be made very small. This is very advantageous for the general trend of higher and higher degree of integration of social circuits in today's society. At the same time, the circuit is simple and it can be used for large-scale production. Said that the cost can be effectively controlled, which also has great advantages for commodity popularization.

However, the system also has certain problems, the transmission frequency is only about $85 \mathrm{KHZ}$, which determines the transmission distance may not be too far, this is the decision of the NE555 and MOS tube, MOS tube is used IRF540N, the best drive of the MOS tube The frequency is 100-200KHZ. If you want to make the transmission distance far away, you need to select a high-frequency MOS tube. The system input is $15 \mathrm{~V}, 0.8 \mathrm{~A}$, so the receiver power will not be too high, this is because NE555 can not pass too much current, otherwise it will burn the chip, later chip power supply and system input can be separated, this problem can be improved.

\section{References}

Hui H, Xueliang H, Linlin T et al., 2011, Research on wireless power transmission transmitter and receiver based on magnetic field resonance coupling, New Technology of Electrical and Electronic Engineering, Vol. 30, No. 1

Kun W, Shuaifei Y, Yebing W, Qibin L, 2013, Design and manufacture of mobile wireless charging devices, Electronic Technology.

Kurs A, Moffatt R, Soljacic M. 2013, Simultaneous mid-range power transfer to multiple devices, Applied Physics Letters, vol. 96, No. 4, pp. 23-30.

Koh K.E., Imura T. and Hori Y., 2014, Impedance matching and power division using impedance inverter for wireless power transfer via magnetic resonant coupling, IEEE Transactions on Industry Applications, Vol. 50, No. 3, pp. 2061-2070.

Maochun Z, Jinhua W, Yawei S. 2009, Review of radio energy transmission technology, Journal of Chongqing Technology and Business University (Natural Science Edition), Vol. 26, No. 4, pp. 485-488

Ming F., 2012, Resonance-coupled power wireless transmission system, Master's thesis, Taiyuan: Taiyuan University of Technology

Michael P T., 2012, Effective capacitive power transfer, IEEE Transactions on Power Electronics, Vol. 27, No. 2, pp. $4906-4913$.

Acknowledgement: The authors are grateful for the funds of the research was received from 2017 Scientific Research Foundation of Xi'an University of Science and Technology (201748)

\section{Biographical notes}

Bo Zhang and Zhong rui Wang are of the Xi'an University of Science and Technology, China.

Received April 2018

Accepted April 2018

Final acceptance in revised form April 2018 